\title{
PENERAPAN DATA MINING REKOMENDASI BUKU MENGGUNAKAN ALGORITMA APRIORI
}

\author{
Saefudin $^{1}$, Donny Fernando ${ }^{2}$ \\ ${ }^{1}$ Jurusan Sistem Informasi, Fakultas Teknologi Informasi, Universitas Serang Raya \\ ${ }^{2}$ Jurusan Rekayasa Sistem Komputer, Fakultas Teknologi Informasi, Universitas Serang Raya \\ Jl. Raya Serang - Cilegon Km. 05 (Taman Drangong), Serang - Banten \\ ${ }^{1}$ saefudin12@gmail.com \\ mr.donny@gmail.com
}

\begin{abstract}
Abstrak - Perpustakaan Kota Cilegon memiliki total koleksi sebanyak 13.792 judul dan 30.135 eksemplar. Dengan buku sebanyak itu pengelolaan rekomendasi buku harus diperhatikan supaya mempermudah petugas perpustakaan dalam merekomendasikan buku untuk pengunjung.Untuk itu diperlukan suatu metode dalam pencarian pola peminjam buku, salah satunya dengan datamining. Penelitian ini bertujuan untuk mencari pola peminjaman buku dengan memanfaatkan algoritma apriori dalam menentukan rekomendasi buku pada Dinas Perpustakaan dan Arsip Daerah (DPAD) Kota Cilegon agar memudahkan petugas perpustakaan dalam menentukan buku yang ingin direkomendasikan pada pengunjung. Metode yang digunakan yaitu Algoritma Apriori dimana metode ini menentukan itemset dari transaksi pinjaman buku yang kemudian dikelompokan dalam tabel itemset1, tabel itemset2, tabel nilai support, tabel nilai confidence dan mendapatkan pola pinjaman buku. Kesimpulan dari penelitian ini adalah dengan menerapkan data mining dapat menghasilkan suatu informasi dari transaksi pinjaman buku pada Dinas Perpustakaan dan Arsip Daerah (DPAD) Kota Cilegon.
\end{abstract}

Kata Kunci : Data Mining, Algoritma Apriori, Assosiation Rule, Rekomendasi Buku, Perpustakaan Kota Cilegon

\section{PENDAHULUAN}

Dinas Perpustakan dan Arsip Daerah (DPAD) Kota Cilegon merupakan salah satu perpustakaan yang ada di provinsi Banten. Perpustakaan kota Cilegon menyimpan berbagai macam buku dan melayani segala permintaan, pinjaman buku dan segala kegiatan yang berhubungan dengan perpustakaan. Perpustakaan Kota Cilegon dilengkapi dengan berbagai fasilitas untuk menunjang kegiatan pembacanya serta memiliki total koleksi sebanyak 13.792 judul dan 30.135 eksemplar. Pengunjung perpustakaan cukup banyak, mulai dari kalangan pelajar maupun umum, khususnya bagi pengunjung yang membutuhkan referensi atau rekomendasi buku untuk dibaca atau dipinjam. Untuk meningkatkan pelayanan salahsatunya adalah penempatan lokasi atau tata letak buku yang sesuai sehingga memudahkan pencarian buku bagi pengunjung perpustakaan.
Rekomendasi buku pada Dinas Perpustakaan dan Arsip Daerah Kota Cilegon dilakukan dengan cara menampilkan buku-buku yang sudah dipilih pada display rekomendasi buku agar menjadi alternatif untuk pengunjung yang bingung dalam menentukan buku yang ingin dibaca. Pemilihan buku rekomendasi saat ini masih dilakukan dengan cara mencari informasi dan melakukan survey pada pengunjung perpustakaan untuk mengetahui buku apa yang akan dipilih dan ditampilkan pada display rekomendasi buku. Dengan melakukan survey tersebut tentunya akan membutuhkan waktu yang tidak sedikit untuk mengetahui kriteria buku apa saja yang akan menjadi rekomendasi. Maka dari itu di perlukan suatu solusi agar dapat mengatasi masalah tersebut, yaitu memudahkan pustakawan dalam menentukan buku rekomendasi.

Solusi untuk mengatasi masalah tersebut adalah dengan menerapkan suatu metode yaitu penerapan data mining dalam penggunaan sistem untuk merekomendasikan 
Tabel 1 Spesifikasi Hardware

pengelompokan atau penempatan buku pada perpustakaan daerah kota Cilegon. Dengan data mining proses pencarian bentuk pola yang tersembunyi (hidden patern) terhadap data setiap transaksi buku yang sebelumnya tidak diketahui jenis datanya yang tersimpan dalam database, data werehouse, atau media penyimpanan informasi yang lain. Beberapa metode dalam data mining. dan yang sering digunakan, yaitu Algoritma Apriori dimana metode ini menentukan itemset dari transaksi pinjaman buku yang kemudian dikelompokan dalam tabel itemset1, tabel itemset2, tabel nilai support, tabel nilai confidence dan mendapatkan pola pinjaman buku.

Tujuan dari penelitian ini adalah memberikan rekomendasi pengelompokan buku pada perpustakaan daerah kota Cilegon menggunakan algoritma apriori untuk menemukan suatu pola menarik dengan cara yang efisien. Pembuatan aplikasi data mining untuk membantu pustakawan dalam menentukan buku rekomendasi untuk pengunjung perpustakaan sehingga dengan sistem ini rekomendasi buku pengunjung menjadi lebih efektif dan efisien.

\section{METODOLOGI PENELITIAN}

\section{A. Analisa Kebutuhan Data}

Berdasarkan hasil wawancara dan observasi yang telah di lakukan diDinas Perpusktakaan dan Arsip Daerah (DPAD) Kota Cilegon, koleksi buku yang ada di perpustakaan menurut data tahun 2018 memiliki total 13.792 judul dan 30.135 eksemplar yang diletakan pada tiap rak-rak berdasarkan klasifikasi pada buku. Dengan buku sebanyak itu ada banyak pengunjung yang datang untuk membaca dan meminjam buku, namun terdapat juga pengunjung yang merasa kebingungan dalam memilih buku dengan jumlah sebanyak itu. Di Dinas Perpustakaan dan Arsip Daerah Kota Cilegon sudah terdapat rekomendasi buku untuk pengunjung agar menjadi pilihan alternatif apabila ingin mengetahui buku yangsedang popoler atau yang banyak diminati saat ini.

\section{B. Analisa Kebutuhan Sistem}

\section{Analisa Pengguna}

Analisa pengguna dimaksudkan untuk mengetahui siapa saja pengguna yang terlibat dalam penggunaan aplikasi data mining. Pengguna dari sistem ini adalah User sebagai petugas perpustakaan di Dinas Perpustakaan dan Arsip Daerah (DPAD) Kota Cilegon yang bertugas dalam melakukan input transaksi buku dan perhitungan data mining.

\section{Analisa Hardware dan Software}

Analisa ini bertujuan untuk mengetahui kebutuhan hardware dan softwate apa saja dalam pembuatan aplikasi data mining. Berikut ini tabel kebutuhan hardware dan software :

\begin{tabular}{|c|l|c|}
\hline No & Nama Hardware & Spesifikasi \\
\hline \multirow{3}{*}{1} & $\begin{array}{l}\text { Laptop AspireAcer } \\
4750 \mathrm{G}\end{array}$ & Processor Core i5 \\
& & Ram $4 \mathrm{~Gb}$ \\
HDD $500 \mathrm{~Gb}$ \\
\hline
\end{tabular}

Tabel 2 Spesifikasi Perangkat Lunak

\begin{tabular}{|c|l|l|}
\hline No & \multicolumn{1}{|c|}{ Nama Software } & \multicolumn{1}{|c|}{ Spesifikasi } \\
\hline 1 & Sistem Operasi & Windows 7 \\
2 & Aplikasi & $\begin{array}{l}\text { Sublime text } \\
\text { xampp }\end{array}$ \\
\hline
\end{tabular}

\section{Analisa Proses Data Mining}

Pada analisa proses Data Mining memerlukan suatu tools yang membantu melakukan proses eksekusi pada operasi data mining berdasarkan model analisis yang telah didefinisikan. Pengolahan data mining ini melakukan proses analisis terhadap suatu data dengan menekankan penemuan suatu informasi pada jenis data yang sangat besar dan tersembunyi yang disimpan dalam suatu database. Ada beberapa faktor yang mendorong perkembangan data mining, diantaranya :

1. Adanya pertumbuhan kumpulan data yang sangat cepat.

2. Hampir semua perusahanan melakukan penyimpanan datanya dalam datawarehouse, sehingga perusahaan sudah memiliki akses ke dalam database.

3. Mengingkatnya penggunaan akses data melalui navigasi web dan internet.

4. Adanya persaingan kompetitif dibidang bisnis dengan tujuan meningkatkan penguasaan pasar dalam perkembanganan era globalisasi dalam segala bidang.

5. Adanya perkembangan teknologi perangkat lunak untuk data mining.

Berikut ini, arsitektur utama komponen sistem data mining, yang terdiri dari :

1. Database, datawarehouse, atau media penyimpanan informasi, yang terdiri dari satu atau beberapa database, datawarehouse, atau data dalam bentuk lain.

2. Database, datawarehose, bertanggung jawab terhadap pencarian data yang relevan sesuai dengan yang diinginkan pengguna atau user.

3. KnowledgeBase (Basis pengetahuan), merupakan basis pengetahuan digunakan untuk panduan dalam pencarian suatu pola.

4. Miningengine merupakan kumpulan modul-modul fungsi yang dapat digunakan dalam proses karakteristik (characterization), klasifikasi (clasiffication), dan analisis kluster (clusteranalysis). Dan modul ini merupakan bagian dari software yang menjalankan program berdasarkan algoritma yang ada.

5. Patternevaluation (Evaluasi pola), adalah bagaian dari komponen yang berinteraksi dengan modul-modul data mining. Juga merupakan bagian dari software yang menemukan pattern atau pola-pola yang terdapat dalam 
database yang di proses pada analisis data mining sehingga menemukan knowledge yang sesuai.

6. Graphical Userinterface (Antar muka), adalah modul komunikasi antara pengguna atau user dengan sistem yang memungkinkan pengguna berinteraksi dengan sistem untuk menentukan proses data mining itu sendiri.

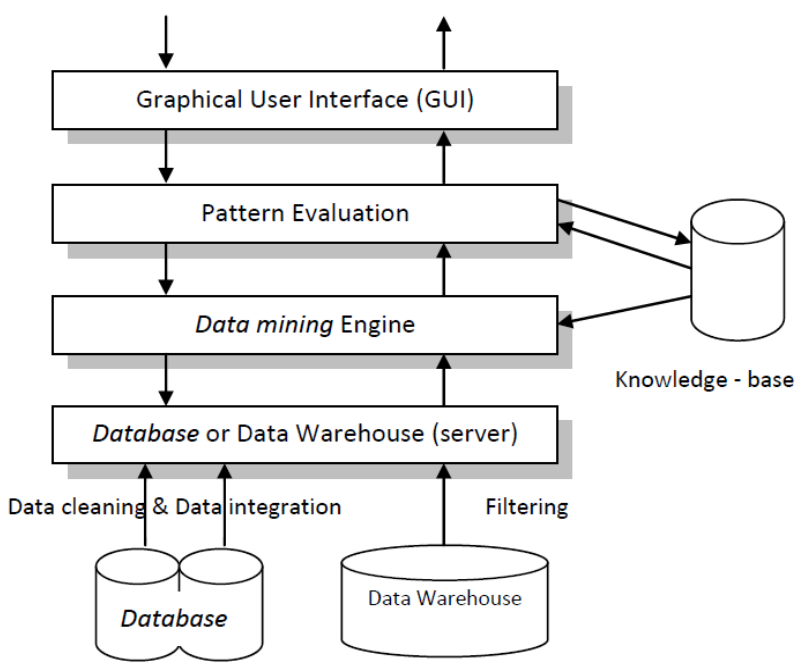

Gambar 1. Arsitektur Data mining (Sumber: Purba, Yugi Trianto. 2008)

\subsection{Aturan Asosiasi (Association rule)}

Dengan meningkatnya kegiatan peminjaman buku pada perpustakaan kota Cilegon, mendorong pihak perpustakaan untuk lebih meningkatkan atau mengontrol ketersediaan kemampuan setiap transaksi, seperti pengelolaan pendaftaran anggota baru, data transaksi peminjaman buku, pengembalian buku, serta kegiatankegiatan lainnya yang berhubungan dengan perpustakaan yang disimpan dalam database. Proses penyimpanan ini tentunya memerlukan ruang (space) database yang lebih besar. Maka dari itu diperlukan teknik-teknik yang secara otomatis dapat menyimpan setiap data transaksi tersebut. Adapun salah satu teknik yang digunakan dalam data mining adalah Aturan Asosiasi (Association Rule).

Adapun metodologi dasar tentang aturan asosiasi terbagi menjadi dua tahapan, yaitu :

1. Tahapan analisis pola frekuensi tinggi

Pada tahapan ini mencari kombinasi item yang telah memenuhi syarat minimum dari nilai support dalam database. Nilai support (penunjang) yaitu persentase item atau kombinasi item yang ada pada database. Nilai support sebuah item diperoleh dengan rumus berikut :

support $(A)=\frac{\text { jumlah transaksi mengandung } A}{\text { jumlah transaksi }}$

Sedangkan nilai dari support 2 item diperoleh dari rumus berikut :Support $(\mathrm{A}, \mathrm{B})=\mathrm{P}(\mathrm{A}$ Ç B $)$

$$
\operatorname{support}(A, B)=\frac{\sum \text { Transaksi mengandung } A B}{\sum \text { Transaksi }}
$$

2. Tahapan pembentukan aturan asosiatif

Tahapan ini terpenuhi apabila semua pola frekuensi tinggi ditemukan, maka dicari aturan asosiatif yang memenuhi syarat minimum untuk confidence dengan menghitung confidence aturan asosiatif "Jika A maka B" $=(\mathrm{A}-\mathrm{-}>\mathrm{B})$.

\subsection{Algoritma Apriori}

Algoritma apriori adalah satu algoritma dasar untuk menemukan frequentitemsets pada aturan asosiasi Boolean. Adapun salah satu ide utama pada algoritma ini adalah :

1. Mencari frequentitemset (himpunan item-item yang memenuhi minimum support.) dari basis data transaksi.

2. Menghilangkan itemset degaan frekuensi yang rendah berdasarkan level minimum support yang telah ditentukan sebelumnya.

Proses selanjutnya adalah membangun aturan-aturan asosiasi dari itemset yang memenuhi nilai minimum confidence dalam suatu basis data. Untuk membentuk kandidat itemset ada dua proses utama yang dilakukan oleh pada algoritma apriori, yaitu :

1. JoinStep (Penggabungan)

Pada proses ini setiap item dikombinasikan dengan item lainnya sampai tidak terbentuk kombinasi lagi.

2. PruneStep (Pemangkasan)

Pada proses ini, hasil dari item yang dikombinasikan tadi kemudian dipangkas dengan aturan yang telah ditetapkan diatas.

\section{HASIL DAN PEMBAHASAN}

\section{A. Penerapan Data Mining}

Data transaksi buku di Dinas Perpustakaan dan Arsip Daerah (DPAD) Kota Cilegon yang telah diperoleh dan dilakukan tahap perhitungan Data mining sehingga menghasilkan aturan asosiasi dengan beberapa langkah sebagai berikut :

1. Menetapkan besarnya besaran minimum support dan minimum confidence. Minimum support yang digunakan yaitu 2 dan minimum confidence yaitu $50 \%$.

2. Menyusun semua frequentitemset yaitu itemset yang memiliki minimum support $>=2$.

3. Pilih aturan asosiasi yang memenuhi minimum support dan minimum confidence dari tabel daftar calon aturan asosiasi.

Tabel 3. Data Transaksi Buku

\begin{tabular}{|c|l|}
\hline Transaksi & \multicolumn{1}{|c|}{ Judul } \\
\hline 1 & $\begin{array}{l}\text { Dua puluh lima keajaiban orang-orang } \\
\text { beriman / Abdul Wadud Kasyful Humam, } \\
\text { Setiap Detik Bersama Allah, Nasihat Asmaul } \\
\text { Husna }\end{array}$ \\
\hline 2 & $\begin{array}{l}\text { Investasi Pada Pasar Modal Syariah, 99 } \\
\text { Sedekah Kreatif : Sedekah Tidak Menunggu } \\
\text { Kaya dan Nanti, }\end{array}$ \\
\hline 3 & $\begin{array}{l}\text { Ringkasan Ihya'ulumuddin, Sejarah } \\
\text { Pendidikan Islam, Perempuan Bertanya Fikih }\end{array}$ \\
\hline
\end{tabular}




\begin{tabular}{|c|c|}
\hline & Menjawab \\
\hline 4 & $\begin{array}{l}\text { Sejarah Pendidikan Islam, Pendidikan Agama } \\
\text { Islam Untuk Perguruan Tinggi, }\end{array}$ \\
\hline 5 & $\begin{array}{l}\text { Doa \& Dzikir Khusus Ibu Hamil, Bagaimana } \\
\text { Memahami Al-Qur'an, Mengolah Rasa } \\
\text { Menggapai Asa : Obat Hati Generasi Masa } \\
\text { Kini }\end{array}$ \\
\hline 6 & $\begin{array}{l}100 \text { Muslim Paling Berpengaruh dan } \\
\text { Terhebat Sepanjang Sejarah, Ringkasan } \\
\text { Ihya'ulumuddin, Sejarah Pendidikan Islam }\end{array}$ \\
\hline 7 & $\begin{array}{l}\text { Bagaimana Memahami Al-Qur'an, Risalah } \\
\text { Shalat Malam\&Mabit, }\end{array}$ \\
\hline 8 & $\begin{array}{l}\text { Sudah Shalat, Kok Tetap Maksiat?, } \\
\text { Perempuan Bertanya Fikih Menjawab, }\end{array}$ \\
\hline 9 & $\begin{array}{l}\text { Islam dan Iman Aturan-Aturan Pokok } \\
\text { Rekonstruksi Epistemologis Rukun Islan dan } \\
\text { Rukun Iman, Sejarah Pendidikan Islam, } \\
\text { Pendidikan Agama Islam Untuk Perguruan } \\
\text { Tinggi }\end{array}$ \\
\hline 10 & $\begin{array}{l}\text { Menuju Kesempurnaan Shalat : Menjaga } \\
\text { Kesempurnaan Shalat dengan Menghindari } \\
\text { Berbagai Kesalahan yang Sering Terjadi } \\
\text { dalam Shalat, , Sejarah Pendidikan Islam }\end{array}$ \\
\hline 11 & $\begin{array}{l}\text { Indahnya Shalat, Sejarah Pendidikan Islam, } \\
\text { Perempuan Bertanya Fikih Menjawab }\end{array}$ \\
\hline 12 & $\begin{array}{l}\text { Mengolah Rasa Menggapai Asa : Obat Hati } \\
\text { Generasi Masa Kini, Perempuan Bertanya } \\
\text { Fikih Menjawab, Bagaimana Memahami Al- } \\
\text { Qur'an }\end{array}$ \\
\hline 13 & $\begin{array}{l}\text { Risalah Shalat Malam\&Mabit, Pelajaran dari } \\
\text { Alam Kubur Mengais Hikmah dari Kisah } \\
\text { Orang-Orang Mati yang Hidup Lagi, } \\
\text { Indahnya Shalat }\end{array}$ \\
\hline 14 & $\begin{array}{l}\text { HUKUM PERDATA ISLAM di } \\
\text { INDONESIA, Nasihat Asmaul Husna, Setiap } \\
\text { Detik Bersama Allah }\end{array}$ \\
\hline 15 & $\begin{array}{l}99 \text { Sedekah Kreatif : Sedekah Tidak } \\
\text { Menunggu Kaya dan Nanti, Perempuan } \\
\text { Bertanya Fikih Menjawab, }\end{array}$ \\
\hline 16 & $\begin{array}{l}\text { Perempuan Bertanya Fikih Menjawab, Sudah } \\
\text { Benarkah Salat Kita?, Nasihat Asmaul Husna }\end{array}$ \\
\hline 17 & $\begin{array}{l}\text { Sejarah Pendidikan Islam, Pendidikan Agama } \\
\text { Islam Untuk Perguruan Tinggi, Bagaimana } \\
\text { Memahami Al-Qur'an }\end{array}$ \\
\hline 18 & $\begin{array}{l}16 \text { Dosa Meninggalkan Salat Wajib / Ahmad } \\
\text { Zacky El-Syafa, Beginilah Cara Menjawab } 6 \\
\text { Pertanyaan Malaikat Di Alam Kubur, Sejarah } \\
\text { Pendidikan Islam }\end{array}$ \\
\hline 19 & $\begin{array}{lll}\text { Rahasia Sukses Berhijrah / Efranjy } \\
\text { Agratama, Ringkasan Ihya'ulumuddin, }\end{array}$ \\
\hline 20 & $\begin{array}{l}\text { Indahnya Shalat, Perempuan Bertanya Fikih } \\
\text { Menjawab, Mengolah Rasa Menggapai Asa : } \\
\text { Obat Hati Generasi Masa Kini }\end{array}$ \\
\hline
\end{tabular}

(Sumber: Data Perpus Kota Cilegon)

Tabel transaksi pada tabel 3 di atas adalah data transaksi peminjaman buku bulan Mei-Juni 2019 berdasarkan kategori Agama.

\section{B. Metode Asosiasi (Association Rule)}

Melalukan perhitungan data dengan Metode Asosiasi (Association Rule) dilakukan dengan menentukan itemset berdasarkan judul buku yang muncul dan dimasukan kedalam daftar calon frequent 1 -itemset :

Tabel 4. Daftar Calon Frequent 1-Itemset

\begin{tabular}{|c|c|c|}
\hline No & Itemset & Support \\
\hline 1 & $\begin{array}{l}\text { Dua puluh lima keajaiban orang-orang } \\
\text { beriman / Abdul Wadud Kasyful } \\
\text { Humam }\end{array}$ & 1 \\
\hline 2 & Setiap Detik Bersama Allah & 2 \\
\hline 3 & Nasihat Asmaul Husna & 3 \\
\hline 4 & Investasi Pada Pasar Modal Syariah & 1 \\
\hline 5 & $\begin{array}{l}99 \text { Sedekah Kreatif : Sedekah Tidak } \\
\text { Menunggu Kaya dan Nanti }\end{array}$ & 2 \\
\hline 6 & Sejarah Pendidikan Islam & 5 \\
\hline 7 & $\begin{array}{l}\text { Pendidikan Agama } \\
\text { Perguruan Tinggi }\end{array}$ & 2 \\
\hline 8 & Sudah Shalat & 1 \\
\hline 9 & Kok Tetap Maksiat? & 1 \\
\hline 10 & Perempuan Bertanya Fikih Menjawab & 5 \\
\hline 11 & $\begin{array}{l}\text { Islam dan Iman Aturan-Aturan Pokok } \\
\text { Rekonstruksi Epistemologis Rukun } \\
\text { Islan dan Rukun Iman }\end{array}$ & 1 \\
\hline 12 & $\begin{array}{l}\text { Menuju Kesempurnaan Shalat : } \\
\text { Menjaga Kesempurnaan Shalat dengan } \\
\text { Menghindari Berbagai Kesalahan yang } \\
\text { Sering Terjadi dalam Shalat }\end{array}$ & 1 \\
\hline 13 & Indahnya Shalat & 3 \\
\hline 14 & Risalah Shalat Malam\&Mabit & 1 \\
\hline 15 & $\begin{array}{l}\text { Pelajaran dari Alam Kubur Mengais } \\
\text { Hikmah dari Kisah Orang-Orang Mati } \\
\text { yang Hidup Lagi }\end{array}$ & 1 \\
\hline 16 & $\begin{array}{lll}\text { HUKUM PERDATA } & \text { ISLAM di } \\
\text { INDONESIA } & & \\
\end{array}$ & 1 \\
\hline 17 & Sudah Benarkah Salat Kita? & 1 \\
\hline 18 & $\begin{array}{l}16 \text { Dosa Meninggalkan Salat Wajib / } \\
\text { Ahmad Zacky El-Syafa }\end{array}$ & 1 \\
\hline 19 & $\begin{array}{l}\text { Beginilah Cara Menjawab } 6 \text { Pertanyaan } \\
\text { Malaikat Di Alam Kubur }\end{array}$ & 1 \\
\hline 20 & $\begin{array}{l}\text { Mengolah Rasa Menggapai Asa : Obat } \\
\text { Hati Generasi Masa Kini }\end{array}$ & 1 \\
\hline
\end{tabular}

Dari tabel 4 di atas kemudian dikelompokan kembali item yang memiliki minimum support yang telah ditentukan yaitu $>=2$. Item-item yang telah memenuhi minimum support dimasukan kedalam daftar frequent 1itemset.

Tabel 5. Daftar Frequent 1-Itemset

\begin{tabular}{|c|l|c|}
\hline No & \multicolumn{1}{|c|}{ Item } & Support \\
\hline 1 & Setiap Detik Bersama Allah & 2 \\
\hline 2 & Nasihat Asmaul Husna & 3 \\
\hline 3 & 99 Sedekah Kreatif : Sedekah & 2 \\
\hline
\end{tabular}




\begin{tabular}{|c|l|c|}
\hline & Tidak Menunggu Kaya dan Nanti & \\
\hline 4 & Sejarah Pendidikan Islam & 5 \\
\hline 5 & $\begin{array}{l}\text { Pendidikan Agama Islam Untuk } \\
\text { Perguruan Tinggi }\end{array}$ & 5 \\
\hline 6 & $\begin{array}{l}\text { Perempuan Bertanya Fikih } \\
\text { Menjawab }\end{array}$ & 3 \\
\hline 7 & Indahnya Shalat & \\
\hline \multicolumn{2}{|l|}{ (Sumber: Data Perpus Kota Cilegon) } \\
\hline
\end{tabular}

Dari daftar frequent 1-itemset kemudian dilakukan proses pencarian pola 2 item yang dibuat menjadi daftar calon frequent 2-itemset.

Tabel 6. Daftar Calon Frequent 2-Itemset

\begin{tabular}{|c|c|c|c|}
\hline No & Item1 & Item2 & Support \\
\hline 1 & $\begin{array}{l}\text { Setiap Detik } \\
\text { Bersama Allah }\end{array}$ & $\begin{array}{l}\text { Nasihat Asmaul } \\
\text { Husna }\end{array}$ & 2 \\
\hline 2 & $\begin{array}{l}\text { Setiap Detik } \\
\text { Bersama Allah }\end{array}$ & $\begin{array}{l}99 \text { Sedekah } \\
\text { Kreatif : Sedekah } \\
\text { Tidak Menunggu } \\
\text { Kaya dan Nanti }\end{array}$ & 0 \\
\hline 3 & $\begin{array}{l}\text { Setiap Detik } \\
\text { Bersama Allah }\end{array}$ & $\begin{array}{l}\text { Sejarah } \\
\text { Pendidikan Islam }\end{array}$ & 0 \\
\hline 4 & $\begin{array}{l}\text { Setiap Detik } \\
\text { Bersama Allah }\end{array}$ & $\begin{array}{l}\text { Pendidikan Agama } \\
\text { Islam Untuk } \\
\text { Perguruan Tinggi }\end{array}$ & 0 \\
\hline 5 & $\begin{array}{l}\text { Setiap Detik } \\
\text { Bersama Allah }\end{array}$ & $\begin{array}{l}\text { Perempuan } \\
\text { Bertanya Fikih } \\
\text { Menjawab }\end{array}$ & 0 \\
\hline 6 & $\begin{array}{l}\text { Setiap Detik } \\
\text { Bersama Allah }\end{array}$ & Indahnya Shalat & 0 \\
\hline 7 & $\begin{array}{l}\text { Nasihat Asmaul } \\
\text { Husna }\end{array}$ & $\begin{array}{l}99 \text { Sedekah } \\
\text { Kreatif : Sedekah } \\
\text { Tidak Menunggu } \\
\text { Kaya dan Nanti }\end{array}$ & 0 \\
\hline 8 & $\begin{array}{l}\text { Nasihat Asmaul } \\
\text { Husna }\end{array}$ & $\begin{array}{l}\text { Sejarah } \\
\text { Pendidikan Islam }\end{array}$ & 0 \\
\hline 9 & $\begin{array}{l}\text { Nasihat Asmaul } \\
\text { Husna }\end{array}$ & $\begin{array}{l}\text { Pendidikan Agama } \\
\text { Islam Untuk } \\
\text { Perguruan Tinggi }\end{array}$ & 0 \\
\hline 10 & $\begin{array}{l}\text { Nasihat Asmaul } \\
\text { Husna }\end{array}$ & $\begin{array}{l}\text { Perempuan } \\
\text { Bertanya Fikih } \\
\text { Menjawab }\end{array}$ & 1 \\
\hline 11 & $\begin{array}{l}\text { Nasihat Asmaul } \\
\text { Husna }\end{array}$ & Indahnya Shalat & 0 \\
\hline 12 & $\begin{array}{l}99 \text { Sedekah } \\
\text { Kreatif : Sedekah } \\
\text { Tidak Menunggu } \\
\text { Kaya dan Nanti }\end{array}$ & $\begin{array}{l}\text { Sejarah } \\
\text { Pendidikan Islam }\end{array}$ & 0 \\
\hline 13 & $\begin{array}{l}99 \text { Sedekah } \\
\text { Kreatif : Sedekah } \\
\text { Tidak Menunggu } \\
\text { Kaya dan Nanti }\end{array}$ & $\begin{array}{l}\text { Pendidikan Agama } \\
\text { Islam Untuk } \\
\text { Perguruan Tinggi }\end{array}$ & 0 \\
\hline 14 & $\begin{array}{l}99 \text { Sedekah } \\
\text { Kreatif : Sedekah } \\
\text { Tidak Menunggu } \\
\text { Kaya dan Nanti }\end{array}$ & $\begin{array}{l}\text { Perempuan } \\
\text { Bertanya Fikih } \\
\text { Menjawab }\end{array}$ & 1 \\
\hline 15 & $\begin{array}{l}99 \text { Sedekah } \\
\text { Kreatif : Sedekah } \\
\text { Tidak Menunggu }\end{array}$ & Indahnya Shalat & 0 \\
\hline
\end{tabular}

\begin{tabular}{|c|c|c|c|}
\hline & Kaya dan Nanti & & \\
\hline 16 & $\begin{array}{l}\text { Sejarah } \\
\text { Pendidikan Islam }\end{array}$ & $\begin{array}{l}\text { Pendidikan Agama } \\
\text { Islam Untuk } \\
\text { Perguruan Tinggi }\end{array}$ & 2 \\
\hline 17 & $\begin{array}{l}\text { Sejarah } \\
\text { Pendidikan Islam }\end{array}$ & $\begin{array}{l}\text { Perempuan } \\
\text { Bertanya Fikih } \\
\text { Menjawab }\end{array}$ & 1 \\
\hline 18 & $\begin{array}{l}\text { Sejarah } \\
\text { Pendidikan Islam }\end{array}$ & Indahnya Shalat & 1 \\
\hline 19 & $\begin{array}{l}\text { Pendidikan Agama } \\
\text { Islam Untuk } \\
\text { Perguruan Tinggi }\end{array}$ & $\begin{array}{l}\text { Perempuan } \\
\text { Bertanya Fikih } \\
\text { Menjawab }\end{array}$ & 0 \\
\hline 20 & $\begin{array}{l}\text { Pendidikan Agama } \\
\text { Islam Untuk } \\
\text { Perguruan Tinggi }\end{array}$ & Indahnya Shalat & 0 \\
\hline 21 & $\begin{array}{l}\text { Perempuan } \\
\text { Bertanya Fikih } \\
\text { Menjawab }\end{array}$ & Indahnya Shalat & 2 \\
\hline
\end{tabular}

(Sumber: Data Perpus Kota Cilegon)

Dari tabel daftar calon frequent 2-itemset di atas dapat dilihat bahwa yang memenuhi syarat minimum support $>=2$ untuk menjadi frequent 2-itemset adalah seperti yang terlihat pada tabel 7 di bawah ini.

Tabel 7. Daftar Frequent 2-Itemset

\begin{tabular}{|c|l|l|c|}
\hline No & \multicolumn{1}{|c|}{ Item 1 } & \multicolumn{1}{|c|}{ Item 2 } & Support \\
\hline 1 & $\begin{array}{l}\text { Setiap Detik } \\
\text { Bersama Allah }\end{array}$ & $\begin{array}{l}\text { Nasihat Asmaul } \\
\text { Husna }\end{array}$ & 2 \\
\hline 2 & $\begin{array}{l}\text { Sejarah } \\
\text { Pendidikan Islam }\end{array}$ & $\begin{array}{l}\text { Pendidikan } \\
\text { Agama Islam } \\
\text { Untuk Perguruan } \\
\text { Tinggi }\end{array}$ & 2 \\
\hline 3 & $\begin{array}{l}\text { Perempuan } \\
\text { Bertanya Fikih } \\
\text { Menjawab }\end{array}$ & Indahnya Shalat & 2 \\
\hline
\end{tabular}

(Sumber: Data Perpus Kota Cilegon)

Setelah semua pola frekuensi tinggi ditemukan, barulah dicari aturan asosiasi yang memenuhi syarat minimum untuk confidence dengan menghitung confidence aturan asosiasif $\mathrm{A} \rightarrow \mathrm{B}$. Nilai confidence dari aturan $\mathrm{A} \rightarrow \mathrm{B}$ diperoleh dari rumus berikut :

Confidence $\mathrm{P}(\mathrm{B} \mid \mathrm{A})=\frac{\Sigma \text { Transaksi mengandung } \mathrm{AB}}{\Sigma \text { Transaksi } \mathrm{A}}$

Tabel 8. Daftar ConfidenceFrequent 2-Itemset

\begin{tabular}{|c|l|c|c|c|}
\hline No & \multicolumn{1}{|c|}{ Item1 =>Item2 } & Support & \multicolumn{2}{|c|}{ Confidence } \\
\hline 1 & $\begin{array}{l}\text { Setiap Detik Bersama } \\
\text { Allah => Nasihat } \\
\text { Asmaul Husna }\end{array}$ & 2 & $\frac{2}{2}$ & $100 \%$ \\
\hline 2 & $\begin{array}{l}\text { Nasihat Asmaul Husna } \\
\text { => Setiap Detik Bersama } \\
\text { Allah }\end{array}$ & 2 & $\frac{2}{3}$ & $66,67 \%$ \\
\hline 3 & $\begin{array}{l}\text { Sejarah Pendidikan } \\
\text { Islam => Pendidikan } \\
\text { Agama Islam Untuk } \\
\text { Perguruan Tinggi }\end{array}$ & 2 & $\frac{2}{5}$ & $40 \%$ \\
\hline 4 & $\begin{array}{l}\text { Pendidikan Agama Islam } \\
\text { Untuk Perguruan Tinggi }\end{array}$ & 2 & $\frac{2}{2}$ & $100 \%$ \\
\hline
\end{tabular}




\begin{tabular}{|c|l|c|c|c|}
\hline 5 & $\begin{array}{l}\text { => Sejarah Pendidikan } \\
\text { Islam }\end{array}$ & 2 & $\frac{2}{5}$ & $40 \%$ \\
\hline 5 & $\begin{array}{l}\text { Perempuan Bertanya } \\
\text { Fikih Menjawab => } \\
\text { Indahnya Shalat }\end{array}$ & 2 & $\frac{2}{3}$ & $66,67 \%$ \\
\hline 6 & $\begin{array}{l}\text { Indahnya Shalat => } \\
\text { Perempuan Bertanya } \\
\text { Fikih Menjawab }\end{array}$ & 2
\end{tabular}

(Sumber: Data Perpus Kota Cilegon)

Dari daftar diatas kemudian menghasilkan suatu asosiasi berdasarkan nilai minimum support $>=2$ dan nilai minimum confidence 50\% kemudain dimasukan kedalam daftar Aturan Asosiasi.

Tabel 9. Daftar Aturan Asosiasi

\begin{tabular}{|c|c|c|c|}
\hline No & Aturan Asosiasi & Confidence & $\begin{array}{c}\text { Korelasi } \\
\text { rule }\end{array}$ \\
\hline 1 & $\begin{array}{l}\text { Jika pengunjung } \\
\text { meminjam buku } \\
\text { "Setiap Detik Bersama } \\
\text { Allah" maka } \\
\text { pengunjung juga akan } \\
\text { meminjam "Nasihat } \\
\text { Asmaul Husna" }\end{array}$ & $100 \%$ & $\begin{array}{l}\text { korelasi } \\
\text { positif }\end{array}$ \\
\hline 2 & $\begin{array}{lr}\text { Jika Pengunjung } \\
\text { meminjam buku } \\
\text { "Nasihat Asmaul } \\
\text { Husna" maka } \\
\text { pengunjung juga akan } \\
\text { meminjam"Setiap } \\
\text { Detik Bersama Allah" }\end{array}$ & $66,67 \%$ & $\begin{array}{c}\text { korelasi } \\
\text { positif }\end{array}$ \\
\hline 3 & 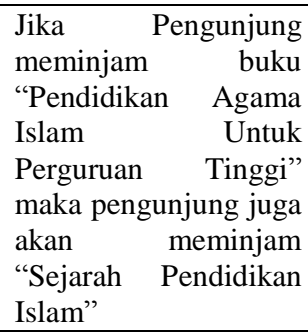 & $100 \%$ & $\begin{array}{c}\text { korelasi } \\
\text { positif }\end{array}$ \\
\hline 4 & $\begin{array}{l}\text { Jika Pengunjung } \\
\text { meminjam buku } \\
\text { "Indahnya Shalat" } \\
\text { maka pengunjung juga } \\
\text { akan meminjam } \\
\text { "Perempuan Bertanya } \\
\text { Fikih Menjawab" }\end{array}$ & $66,67 \%$ & $\begin{array}{c}\text { korelasi } \\
\text { positif }\end{array}$ \\
\hline
\end{tabular}

(Sumber: Data Perpus Kota Cilegon)

Hasil dari analisa sistem yang mencari pola pinjam pengunjung berdasarkan data transaksi buku pada bulan Mei - Juli 2019 dijelaskan bahwa buku yang sering dipinjam bersamaan adalah:

a. jika pengunjung yang meminjam buku "Setiap Detik Bersama Allah", maka pengunjung juga akan meminjam buku "Nasihat Asmaul Husna" dengan tingkat confidence $100 \%$,

b. jika pengunjung yang meminjam buku "Nasihat Asmaul Husna", maka pengunjung juga akan meminjam buku
"Setiap Detik Bersama Allah" dengan tingkat confidence $66,7 \%$,

c. jika pengunjung yang meminjam buku "Pendidikan Agama Islam Untuk Perguruan Tinggi", maka pengunjung juga akan meminjam buku "Sejarah Pendidikan Islam" dengan tingkat confidence $100 \%$,

d. jika pengunjung yang meminjam buku "Indahnya Shalat", maka pengunjung juga akan meminjam buku "Perempuan Bertanya Fiqih Menjawab" dengan tingkat confidence $66,7 \%$.

\section{KESIMPULAN}

Dari hasil penelitian mengenai penerapan data mining rekomendasi buku pada Dinas Perpustakaan dan Arsip Daaerah (DPAD) Kota Cilegon menggunakan algoritma apriori dapat diambil kesimpulan sebagai berikut :

1. Aplikasi data mining ini berfungsi sebagai pemberi rekomendasi buku berdasarkan itemset buku yang sering dipinjam sehingga petugas perpustakaan bisa menentukan buku apa saja yang bisa dijadikan rekomendasi untuk pengunjung perpustakaan. Aplikasi ini juga dapat digunakan sebagai pemberi rekomendasi dalam penambahan buku atau koleksi baru atau yang paling banyak diminati oleh pengunjung perpustakaan.

2. Penerapan data mining menggunakan algoritma apriori dapat digunakan untuk mengolah database transaksi peminjaman buku untuk menemukan suatu pola kombinasi transaksi buku yang sering dipinjam sehingga dapat dijadikan sebagai sebuah informasi yang berguna.

\section{REFERENSI}

[1]. A.S Rosa dan Salahuddin M, (2011). Modul Pembelajaran Rekayasa Perangkat Lunak (Terstruktur dan Berorientasi Objek), Modula, Bandung.

[2]. Arief, M.Rudianto. (2011). Pemrograman Web Dinamis Menggunakan Php dan Mysql. Yogyakarta: ANDI.

[3]. Dinas Perpustakaan Dan Arsip Daerah, (2017). Sejarah [Online].

[4]. Herlawati\& Widodo.(2011). Menggunakan UML.Informatika. Bandung

[5]. Kusrini dan Luthfi Taufiq Emha, (2009), "Algoritma Data Mining”, Andi, Yogyakarta.

[6]. Mandias, G. F. dkk. (2018). Analisa Pola Peminjaman Buku di Pepustakaan Universitas Klabat Menggunakan Algoritma Apriori. Program Studi Sistem Informasi, Universitas Klabat, Airmadidi. 
[7]. Nugroho.Adi. (2009). Rekayasa Perangkat Lunak Menggunakan UML \& Java. Yogyakarta: Andi Offset.

[8]. Santoso, B. (2007), Data Mining:Teknik pemanfaatan data untuk keperluan bisnis, Graha Ilmu, Yogyakarta.

[9]. Santoso, Heroe. (2017). Data Mining Penyusunan Buku Perpustakaan Daerah Lombok Barat Menggunakan Algoritma Apriori.Seminar Nasional TIK dan Ilmu Sosial (SocioTech) 10 Oktober 2017.

[10]. Srikanti, Esis. dkk. (2018). Penerapan Algoritma Apriori Untuk Mencari Aturan Asosiasi Pada Data Peminjaman Buku Di Perpustakaan. Jurnal Ilmiah Rekayasa dan Manajemen Sistem Informasi, Vol. 4, No. 1, Februari 2018.

[11]. Saefudin, Septian DN (2019). Penerapan Data Mining Dengan Metode Algoritma Apriori Untuk Menentukan Pola Pembelian Ikan, Jurnal Sistem Informasi (JsiI), Vol.6, No.2, September 2019.

[12]. Tumini.dan Lestanto, E. (2017). Aplikasi Data Mining Menggunakan Metode Association Rule Dan Algoritma Apriori Berbasis Web Pada Perpustakaan Di SMA Negeri 1 Bungursari. Jurnal Informatika SIMANTIK Vol. 2 No. 2 September 2017.

[13]. Yanto, Robi. dan Kesuma, H. D. (2017).Pemanfaatan Data Mining Untuk Penempatan Buku Di Perpustakaan Menggunakan Metode Association Rule.Daftar Pustaka Jatisi, Vol. 4 No. 1 September 2017. 